\title{
Research on Equipment Maintenance Support Information System for PHM
}

\author{
Chen Meng, Xu Li ${ }^{\text {a)}}$, Cheng Wang \\ Army Engineering University, Shijiazhuang 050003, China \\ a) Corresponding author: 764468402@qq.com
}

\begin{abstract}
In order to achieve state-based maintenance of the equipment maintenance support system, this paper proposes to build an equipment maintenance support information system based on networked and knowledgeable technologies. The establishment of equipment maintenance support information system needs to address two major issues: First, achieve the network and equipment status and operational information collection and sharing of test equipment at all levels; Second, achieve knowledge-based for the status information, test information, environmental information and design information and other equipment information The and further implementation of maintenance decision support and job guidance. This paper focuses on the system architecture of the equipment maintenance support information system, the networking of automatic test equipment, the acquisition and sharing of equipment status and operation information, and the knowledge-based technology of the equipment maintenance support information system and studies the realization of the maintenance support information system for PHM equipment maintenance.
\end{abstract}

Key words: PHM; Equipment Maintenance Information System, Networking; Knowledge; Information Collection and Sharing.

\section{INTRODUCTION}

The "cognitive level sharing" and "timely guarantee" proposed by the future integrated joint operations require the establishment of a unified information system for equipment research and development, use of troops, and repair agencies at all levels to achieve information sharing throughout the life cycle of equipment and achieve health. The purpose of comprehensive improvement of management and equipment quality assurance [1]. The traditional planned maintenance based on the restoration of the equipment's inherent technical status has been unable to meet the requirements of modern joint operations for equipment and technology support. Comprehensive analysis and processing based on the equipment life cycle information to obtain real-time health status-based maintenance to improve maintenance efficiency has become development trend. The equipment maintenance guarantee is changed from the traditional "recovering the inherent technical status" to "acquisition of information (equipment use status, maintenance and repairs, force support forces, maintenance equipment, expert support, etc.), transmission, and knowledge, forming a maintenance decision. With the guidance of "mainly to achieve state-based maintenance, so that the maintenance benefits multiply exponentially, to achieve maintenance operations "front" simplification.

With the continuous advancement of the informatization construction of our military in the future, it will become necessary to build an information system for maintenance of equipment maintenance. On the maintenance and protection information system platform, all kinds of information such as equipment design, historical maintenance, and safeguard application have been existed and updated in real time. Operation status information can be inserted at any time, remote expert support is readily available, and maintenance support information at all levels is unified. Information system platform flow, all levels of equipment repair agencies through the network of information support equipment, test equipment, you can obtain full-dimensional protection information, and get a scientific maintenance support conclusion, the maintenance of the support system to play an efficient all-round support. The establishment of equipment maintenance support information system needs to focus on solving two problems: First, 
to achieve networked repair and test equipment and equipment status and operation information collection equipment at all levels, and use it as a network node in the maintenance support information system; The knowledge of equipment maintenance support information, through the processing and processing of equipment status information, test information, environmental information, and design information, completes state-based life prediction, fault diagnosis, intelligent maintenance decisions, and maintenance case generation. Relevant network transmission, network services, navigation and positioning, battlefield environment protection, and information security will be solved by the PLA's informatization infrastructure.

\section{EQUIPMENT MAINTENANCE INFORMATION SYSTEM}

Modern information system refers to a system that acquires, transmits, processes, stores, distributes, and uses information through sensors, communication networks, computers, and software. The elements that make up an information system are sensors, communication networks, computers, and software. The acquisition, transmission, processing, storage, distribution, and use of information are not only the functions and roles of information systems, but also reflect the structural order among various components. The core of the contact with various elements is information [2].

The equipment maintenance and support information system are an information system that supports maintenance and protection agencies to carry out maintenance support and operation of equipment. It uses network technology to integrate the development and production units of equipment, operational use units, and repair agencies at various levels of the armed forces into an integrated unit to achieve equipment design and manufacturing, life-long use status, maintenance and repair, force support, maintenance equipment, and equipment maintenance. The sharing of equipment maintenance information and maintenance process information such as decision-making, guidance, expert support, etc. provides a complete state of equipment awareness for the maintenance and support organization, supports the maintenance and protection organization to obtain information advantages and decisionmaking advantages, and lays the foundation for obtaining optimal maintenance support effects.

The main sources of information acquisition in the equipment maintenance support information system are repair and test equipment at all levels, equipment status and operation information collection equipment, and equipment development and production unit information and data services. The main content of information processing and processing is to transform the equipment life cycle information. Knowledge for maintenance support.

\section{NETWORKED AND KNOWLEDGEABLE TECHNOLOGY OF EQUIPMENT MAINTENANCE SUPPORT INFORMATION SYSTEM}

The information view of the equipment maintenance support information system is shown in Figure 1. Each network node is hung on the Web Services bus. The equipment development and production units provide equipment design and manufacturing, maintenance requirements, fault diagnosis, fault isolation, etc. (online Support) information; adapter development unit to provide equipment (subsystem) test conditions, test flow description, adapter description and other information; basic level repair agencies use information support equipment to complete the equipment status and operating information acquisition, and upload to the network service bus; The secondary and depot-level repair organizations use ATE to complete the testing of the equipment's overall performance parameters and sub-system (major components) technical parameters, and to upload test, maintenance procedures, fault cases, ATE description and test function service description, etc. Information to the network service bus. 


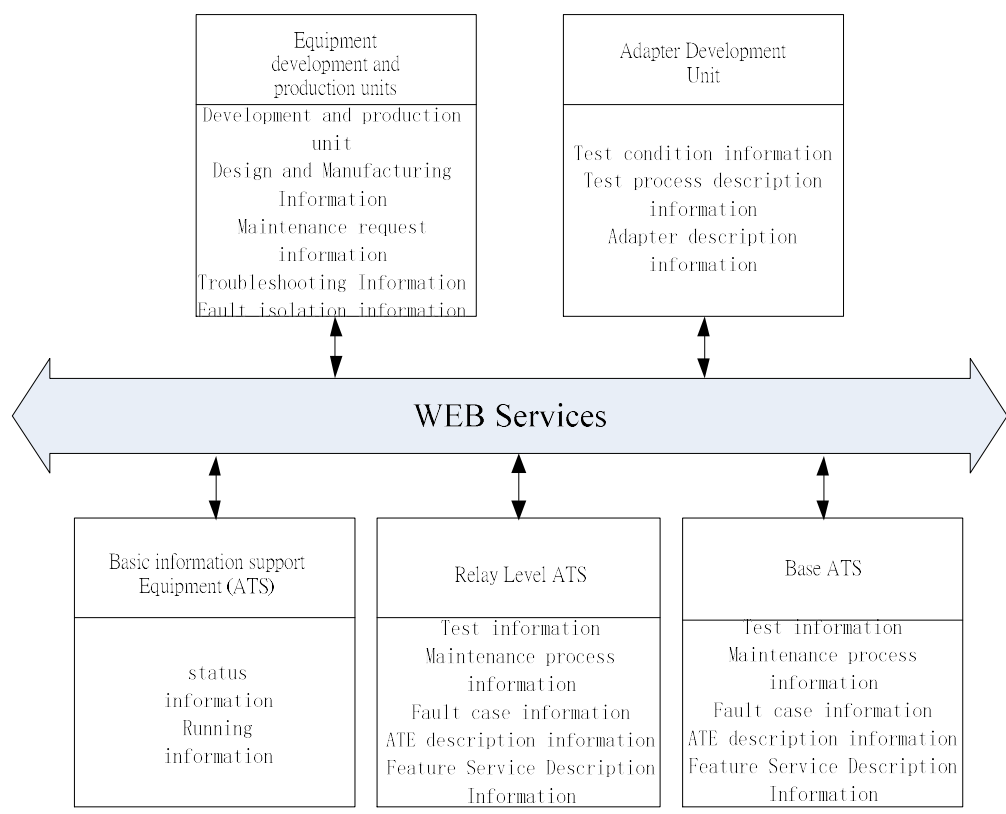

FIG.1 Equipment Maintenance Information System Information View

\section{Equipment Maintenance Information System Architecture}

The equipment maintenance support information system adopts a service-oriented architecture, as shown in Figure 2 [3].

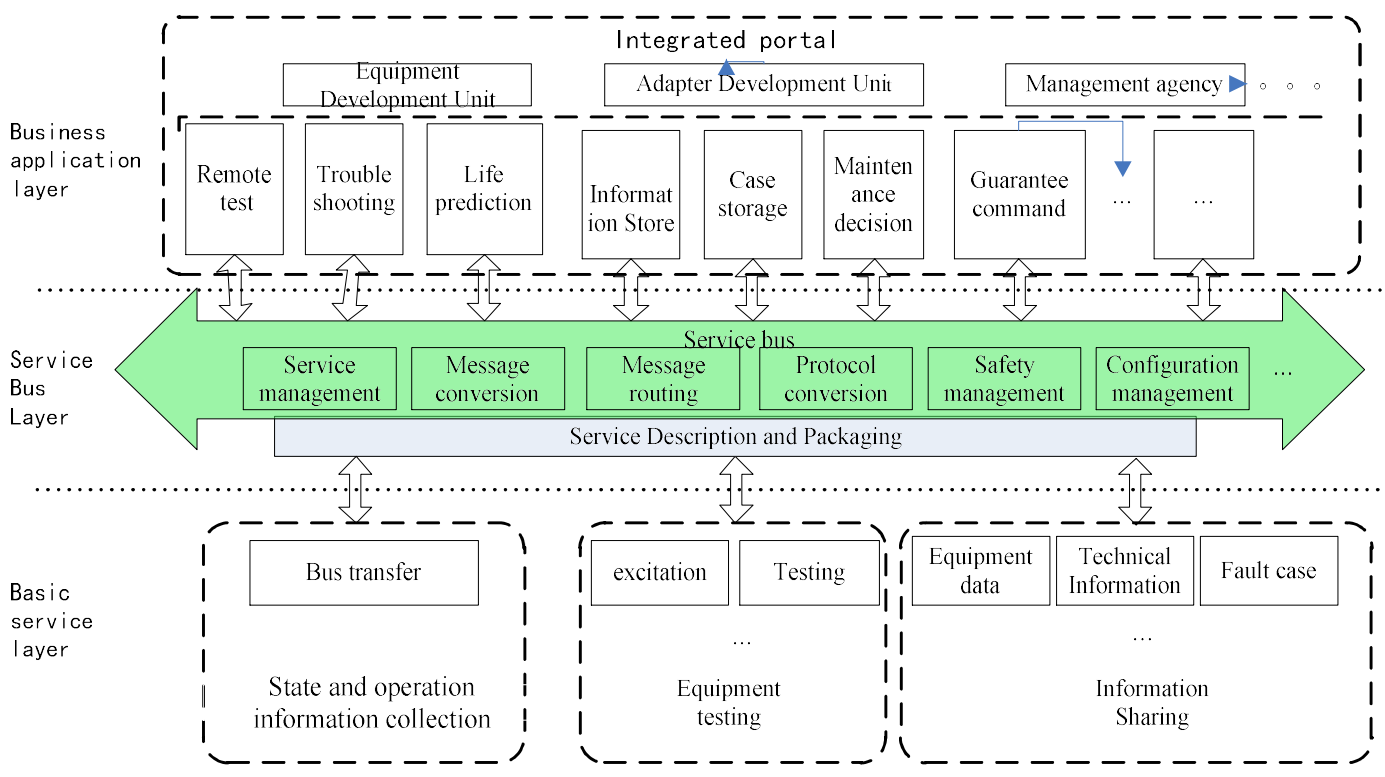

FIG.2 System architecture of equipment maintenance support information system 


\section{Networking Requirements for Automatic Test Equipment}

According to Figure 2, the automatic test equipment as a network node needs to provide external test service and information sharing services. The test function service encapsulates the test/incentive function provided by ATE as a service. It abstracts the test/incentive function, ignores the implementation details of the specific function, and provides a standard service model. The service can be combined as needed. Create a new service. The test function service enables the ATE test function to be published in the form of a binary service, which satisfies the need for cross-platform operation of the networked test and equipment test program. The information sharing service refers to the overall performance parameters of the equipment and the technical parameters of the sub-systems (most of the components), maintenance procedures, fault case information, ATE descriptions, and test function service descriptions, which are published in the form of text services and provide decision support for equipment maintenance support. Information sharing services also include receiving maintenance decisions and guidance information to provide technical support for equipment maintenance support operations.

\section{Equipment status and operation information collection and sharing}

In order to reduce equipment hardware costs and space requirements, equipment status and operational information collection, and to support the replacement of basic unit-level repair agencies for the performance of replacement equipment (site replaceable unit, LRU) as the goal, the requirements for information acquisition equipment the scale of the internal test system (BIT) is as simple as possible. On the other hand, in the BIT design, the decentralized and independent conventional BIT structure can no longer meet the needs of the equipment maintenance and support information system. Instead, it should adopt a layered and integrated organizational structure, composed of LRUs (combinations, circuit boards, and ministries). Components) BIT and system-level BIT are formed from bottom to top and have a standard external communication interface. The structure of the equipment status and operation information collection system is shown in Figure 3.

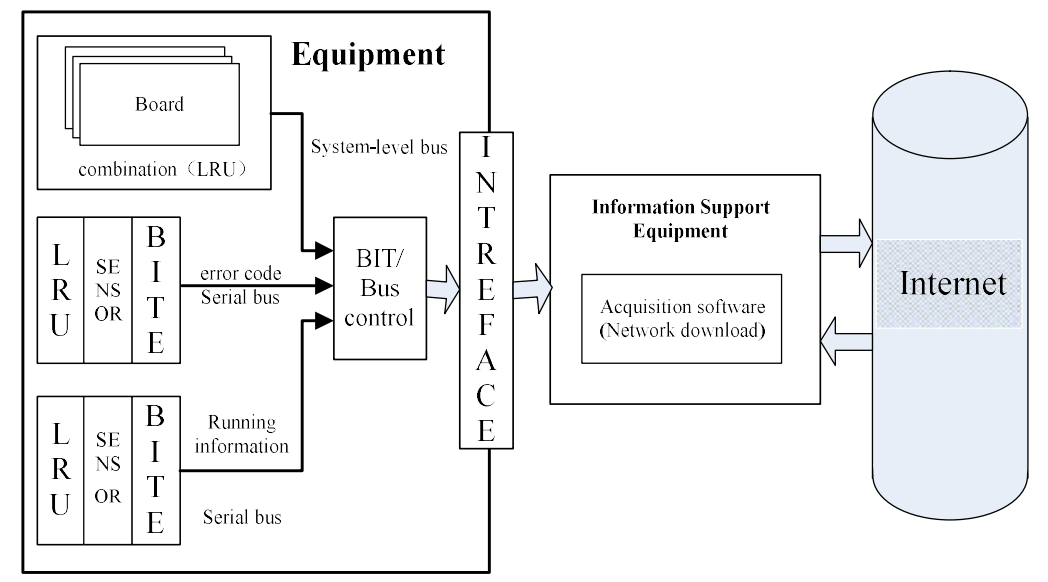

FIG.3 Schematic diagram of equipment status and operation information collection system

For electronic systems in equipment, LRU may be a combination itself (such as microwaves), or it may be a combination of internal circuit boards (such as communications). This type of system BIT performs hierarchical test and diagnosis through system-level test and maintenance buses. For equipment in the electromechanical system, LRU is usually a component. This type of system forms a fault code through a component-level BITE and sends it to the serial bus. For the core component, its operating status information is sent to the serial bus through BITE.

The equipment diagnosis interface should contain a variety of serial buses (such as RS422, CAN) to meet the communication needs of common equipment BIT, but the number of serial buses contained in the equipment diagnostic interface and its communication protocol, interface hardware structure should have a unified The standard.

The information support equipment completes the collection of equipment status and operation information through the equipment diagnostic interface. The equipment, as a network node, also needs to provide information 
sharing services externally, and publish the collected information in the form of a text service and upload it to the network to provide maintenance decision-making services. Support; At the same time receive maintenance decision and guidance information, provide technical support for equipment maintenance support operations. The data acquisition software of the information support equipment can be downloaded via the network to achieve the collection of different equipment information.

\section{Knowledge Management Technology of Equipment Maintenance Support Information System}

In 1998, the World Bank launched the "World Development Report 1998 - Knowledge for Development", expounding the differences between data, information and knowledge. The report states that: The data is unorganized numbers, words, sounds, images. Etc.; information is data (meaningful data) that is arranged and processed in a meaningful form; knowledge is information for production (meaningful information). Information can be transformed into knowledge after being processed and applied to production [4]. The equipping of the equipment maintenance support information system is to process and analyze the equipment's status information, test information, environmental information, and design information to form a knowledge that directly guides the equipment maintenance and maintenance decision-making and maintenance operations. The knowledge model of the equipment maintenance support information system is shown in Figure 4.

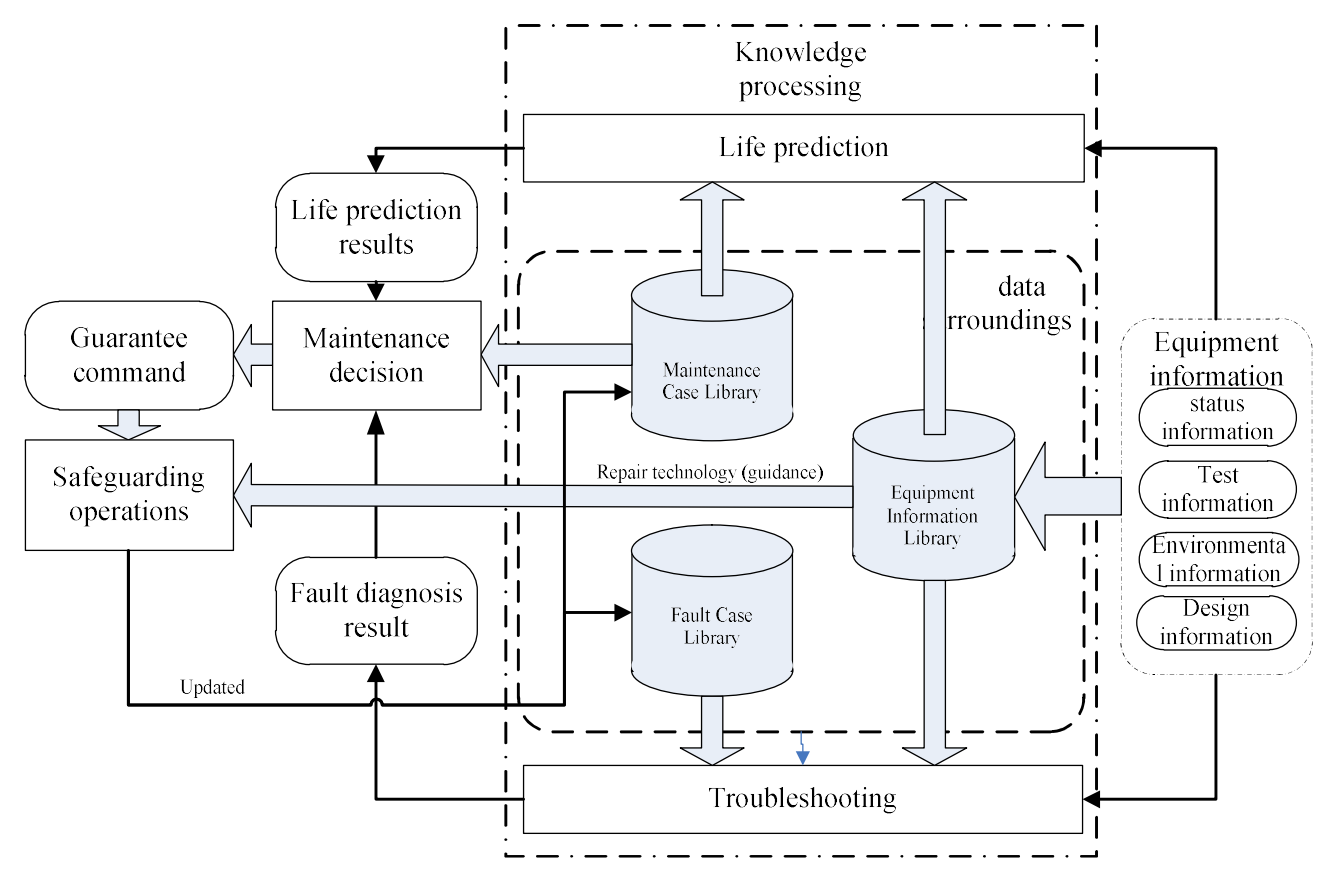

FIG.4 Knowledge model of equipment maintenance support information system

The knowledge processing of the equipment maintenance support information system is mainly achieved through processes such as fault diagnosis, life prediction, and information screening. Life prediction, equipment real-time information, historical data and maintenance cases processed through life prediction model to get life prediction results; fault diagnosis, equipment real-time information, historical data and fault cases processed through fault diagnosis model to get fault diagnosis results; information screening, according to maintenance decision And operational requirements, screening equipment maintenance technical data and job instructions. According to the life prediction results, fault diagnosis results and historical cases, the maintenance decision can be easily made; the scientific maintenance decision, supplemented by the selected equipment technical data and job guidance, ensure the efficient completion of the protection operation. After the security operations are completed, the latest maintenance 
cases and failure cases are enriched in the maintenance case base and failure case base, and the knowledge is updated.

\section{CONCLUSION}

In order to speed up the Informa ionization of our military and construct an equipment maintenance support information system, this paper proposes an architecture of the equipment maintenance support information system, applies service-oriented thinking to the equipment maintenance support information system, and analyzes the network of automatic test equipment. , Equipment status and operation information acquisition and sharing, equipment maintenance information system knowledge technology and implementation approach.

\section{ACKNOWLEDGEMENTS}

Fund Project: Funded by the National Natural Science Foundation of China (61501493)

\section{REFERENCES}

1. Meng Chen, Wang Cheng, Equipment Maintenance Support Information System Networking, Knowledge Technology [C] Equipment Inspection, Fault Diagnosis and Maintenance Support Symposium, China, January.06. 2016.

2. Department of Electronic Information, Department of General Armament Department. Information System ---Building a Foundation for Combat Capability [M]. Beijing: National Defense Industry Press, 2011, 6:17-18.

3. Liu Fujun. Research on Service-Oriented Key Technology of ATS Architecture[D]. Ordnance Engineering College, 2011,12.

4. Zhang Bo. Virtual Information Services for Agricultural Researchers [D]. Chinese Academy of Agricultural Sciences, 2010, 6 . 